\title{
Inspirational molecules
}

\author{
Harry Kroto, buckminsterfullerene and an enduring legacy.
}

Sir Harry Kroto, one of the discoverers of $\mathrm{C}_{60}$, died on 30 April 2016 aged 76. An enthusiastic advocate for the importance of science, his discovery of the spherical buckminsterfullerene stands as a landmark in the evolution of nanotechnology.

Kroto was born Harold Walter Krotoschiner on 7 October 1939 in Wisbech, a small village in Cambridgeshire, and grew up in Bolton. He read Chemistry at the University of Sheffield, graduated in 1961 and completed a $\mathrm{PhD}$ in spectroscopy at the same institution in 1964. After postdoctoral positions at the National Research Council in Ottawa and Bell Labs in the US, Kroto returned to the UK to take up a position at Sussex University in $1966^{1}$.

Initially, Kroto was interested in the detection and characterization of cyanoacetylene chains such as $\mathrm{HC}_{5} \mathrm{~N}$ and $\mathrm{HC}_{7} \mathrm{~N}$, which had been found in interstellar space. In 1985, Robert Curl invited Kroto to Rice University where he met Richard Smalley, who had recently developed his cluster beam apparatus. Kroto thought that if they used the apparatus to produce a plasma from graphite, they could establish the role of carbon stars in the genesis of interstellar molecules. What they actually found was completely unexpected. The vaporization of graphite resulted in the formation of several sphere-shaped molecules, and on noticing sharp peaks for clusters of 60 and 70 carbon atoms in the mass spectra, the team optimized the procedure to favour the formation of 60 -atom clusters. Kroto, Smalley, Curl, Sean O’Brien and Jim Heath - or 'the football team', as Kroto called them - published their initial paper, simply titled ' $\mathrm{C}_{60}$ : Buckminsterfullerene', in Nature in $1985^{2}$.

\section{"I had the strong gut feeling that it was so beautiful a solution that it just had to be right."}

Both Kroto and Smalley came up with the same modelled structure, a truncated icosahedron made up of 20 hexagons and 12 pentagons - just like a football, the enduring image that sits at

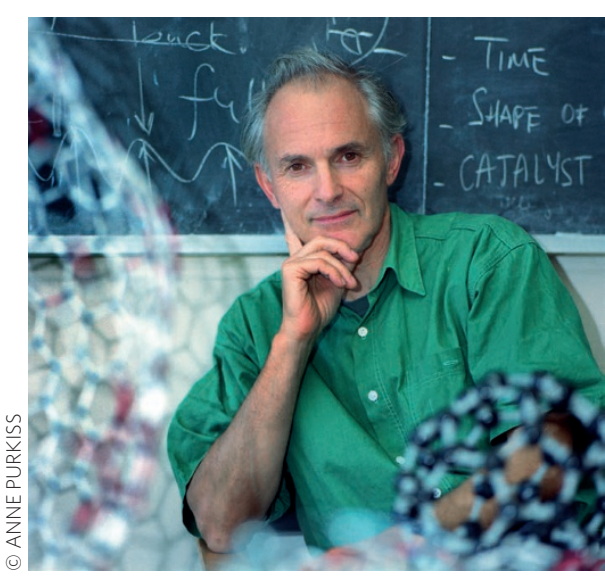

Kroto was passionate about education and public engagement - he was worried about what would be the 'Meccano' for the next generation of scientists ${ }^{1}$. After he received the Nobel Prize he devoted a lot of time to these endeavours and was well known for his engaging lecture style.

In 1995, Kroto founded the Vega Science Trust ${ }^{3}$ and later the Global Educational Outreach for Science, Engineering and Technology (GEOSET; www.geoset.info), which created TV and online content about all aspects of science. He understood the potential the Internet offered for the democratization of broadcasting. In many respects, this web-based platform was ahead of its time, and was limited by connection speeds in the 1990s. Although no longer active, these projects still contain a wealth of resources for science education, including conversations with luminaries such as Fred Sanger and Richard Feynman, scientific debates such as 'Nanotechnology: The next big thing', and even a collaboration with Manchester United to exploit the uncanny resemblance of $\mathrm{C}_{60}$ to a football.

Although the practical applications of $\mathrm{C}_{60}$ have remained limited, its discovery changed our perception of the behaviour of carbon and paved the way for work on carbon nanotubes and graphene. Considering Kroto's original motivations to understand the formation of molecules in outer space, it seems fitting that two recent papers have now detected ${ }^{6}$ and confirmed ${ }^{7}$ the astronomical role of $\mathrm{C}_{60}$. Kroto worked on other nanoscience advances, but possibly more important than his scientific legacy is the enduring inspirational impact of a molecule shaped like a football, an iconic image that he used to communicate his love of science to great effect.

References

1. Sir Harold Kroto - Biographical. Nobelprize.org; http://go.nature.com/P51Tpf

2. Kroto, H. W., Heath, J. R., O’Brien, S. C., Curl, R. F. \& Smalley, R. E. Nature 318, 162-163 (1985).

3. A Round Peg In A Square Hole - 2002 Faraday Award Lecture; http://go.nature.com/MBYYev

4. Krätschmer, W., Lamb, L. D., Fostiropoulos, K. \& Huffman, D. R. Nature 347, 354-358 (1990).

5. Hargittai, I. Candid Science: Conversations with Famous Chemists (Imperial College Press, 2000).

6. Cami, J., Bernard-Salas, J., Peeters, E. \& Malek, S. E. Science 329, 1180-1182 (2010).

7. Campbell, E. K., Holz, M., Gerlich, D. \& Maier, J. P. Nature 523, 322-323 (2015). 